\title{
Investigating Informality in Construction: Philosophy, Paradigm and Practice
}

Thayaparan Gajendran and Graham Brewer, (School of Architecture and Built Environment University of Newcastle, Australia)

Goran Runeson, (School of the Built Environment, University of Technology Sydney, Australia)

Andrew Dainty, (Department of Civil and Building Engineering, Loughborough University, UK)

\begin{abstract}
The complex interrelationships commonly enacted as a consequence of project team activity take a number of different forms, including those formally dictated by contract conditions. However it is becoming increasingly apparent that project performance is affected by informal relationships, though their investigation is notoriously difficult. This paper proposes that these difficulties arise partly from the nature of the informalities themselves, but also as a consequence of the philosophical position taken by researchers and their consequent methodological/paradigmatic posture, and its impact upon those being studied. It consequently proposes a subjectivist investigative framework that accommodates multiple philosophical points of departure, matching them to a range of alternative methodologies, and indicates the desirability of blending to reflect the peculiarities of each context under investigation. The framework also accommodates the practicalities of putting complex methodologies into action. The paper concludes that this framework presents opportunities to conduct rigorous in-situ investigations of informality at work, leading to authentic and deep insights that would otherwise remain unseen
\end{abstract}

Keywords: Informality, Methodology, Method, Construction

\section{Introduction}

Construction project organisations are characterised by complexity, interconnections and uncertainty. The connectivity and interdependency between multiple sub-systems organisational, technical, or social - together with their positioning as part of uncertain and dynamic socio-cultural-political environments, poses considerable difficulties in understanding and predicting the overall behaviour of a construction project organisation (Geraldi 2008). Indeed, many recent studies have adopted complexity frameworks (Bresnen, Goussevskaia, and Swan 2005; Marrewijk et al. 2008; Baccarini 1996; Remington, Zolin and Turner 2009) and qualitative research methodologies (Denizen and Lincoln 2005) as a way to better conceptualise and understand projects as complex, socially constructed realities (Cooke-Davis et al 2007; Small and Walker 2010). Such approaches can develop significant insights into influential project behaviours including issues relating to knowledge sharing, communication, and relationship building.

However, such studies can be challenged when confronted with the complexity of informalities in these construction project environments. The key element of 'informality' refers to the informal, casual or unofficial activities that occur in business firms, industries, societies and the economy as a whole. The conceptualisation of 'informality' is discipline specific, and in construction management, informality is implicit in a number of research areas e.g. communication (Gorse and Emmitt 2007), safety practices (Lingard and Rowlinson 2005), gender/ethnicity based research (Byrne, Clarke, and Meer 2005; Pink et al. 2010), procurement/recruitment practices (Bresnen et al. 1986), knowledge management etc (Senaratne and Sexton 2008; Bresnen et al. 2003). Moreover, some informality in 
projects may be invisible or implicit, and can produce irreconcilable paradoxes that evade and challenge identification and inquiry (see Small and Walker 2010; Bourne \& Walker 2005; Alderman \& Ivory 2007; Bresnen 2009). It is suggested in this paper that studies into informality could build on recent qualitative and complexity approaches and aid in better understanding project organisations.

In general, there has been a recent, burgeoning interest in 'informality' research in the construction management discipline (Chan and Räisänen 2009). The need for such a research focus arises from the recognition of inadequacies in current approaches to studying construction organisations (Dainity 2008) and gaps in developing meaningful understanding or solutions to many of the complex issues facing construction projects (Berggern and Soderlund 2008; Moldoveanu 2004). In this paper, the concepts and practices of 'informality' are reviewed from Economics, Urban Studies and Organisational Theory domains to develop a layered and contextual understanding of informality. The conceptualisation is notably influenced by both economic and sociological perspectives, and subjected to alternative philosophical paradigms. As O'Leary (2004) suggests "without an appreciation of how attributes, positions of power and privilege, and worldviews conspire to create subjectivities, researchers can easily fall into the trap of judging the reality of others in relation to their own reality" (p. 47). This implies that examining informality from two different worldviews may lead to two different, but equally relevant and meaningful outcomes. Deeper the sociological perspective assumed by a research, greater the need for the researchers to evaluate their philosophical predispositions/biases in constructing the research strategy. Such an approach provides a much-needed subjective relevance, while maintaining high levels of dependability, authenticity, transferability and auditability (O'Leary 2004).

The choice of an appropriate research paradigm in designing a strategy/method to study 'informality' is critical to producing meaningful outcomes. However, it is equally important to accommodate the practicality of the research design. Indeed, explicit accounts of how to research informality in construction are limited (see Chan and Räisänen 2009, Rooke, Koskela and Kangioglou 2009). Aligning the conceptual research design to the operational research design is a frequent challenge faced by researchers (see Gorse and Emmitt 2007, 2009; Pink et al. 2010). In some instances, the execution of the most appropriate conceptual research design may prove impractical or impossible. Such practical challenges can arise from the unwillingness of subjects to cooperate in the study (due to commercial sensitivity, discomfort of participants with in-depth study and profiling), and challenges posed by the national/institutional ethical protocols (prohibiting research based on concerns of privacy, risk, benevolence etc) (Australian Government 2007). This paper builds on the extensive intellectual debates that have taken place about the choice, relevance, understanding and adequacy of research methodologies when studying construction phenomena (see Rooke \& Kagilogou 2007; Dainty 2008; Rooke, Koskela and Kagilogou 2009). Much of this debate is central to designing methodologies to study informality from a social perspective.

This paper explores three interrelated aspects critical for designing research approaches to study 'informality'. They are: (a) a conceptual understanding of 'informality' in project organisations; (b) the worldviews underpinning the ontological and epistemological positions relating to the concept of 'informality'; and, (c) the practical design of appropriate research methods to explore informality within various worldviews. These three aspects are reviewed in the context of selected studies that examine informalities in construction. It concludes by providing an overarching framework to identify appropriate research methods to study informality in construction. In doing so, it consciously avoids rigidly prescribing the 'best' method for studying informality issues as a way of challenging misleading and naïve approaches-instead offering multiple combinations of research approaches and methods that provide both rigour and flexibility. 


\section{Concept of 'Informality': A Review}

'Informality' can be understood and defined from a variety of perspectives. By reviewing definitions and attributes of informality from other disciplines, this paper develops a rigorous conceptual basis for informality as part of the construction domain. The aim is neither to unearth the 'roots' of informality research, nor to give an in-depth account of informality research in other disciplines. Rather, the aim of the paper it is to generate a broader perspective of informality in order to identify the alternative paradigms/worldviews that underpin it. This then provides an opportunity to develop research approaches that can unearth informalities and identify resulting paradoxes in the construction environment.

To this end, three perspectives on informality are reviewed here: urban informality, economic informality, and organisational informality. The study of 'urban informality' is about examining social actors and forms of social organisation in urban areas (Alsayyad 2004). Urban informality is "a way of life [and] may be approached from three interrelated perspectives: the physical structure, comprising a population base; a system of social organization, involving a characteristic social structure and related patterns of social relationships; and a set of attitudes and ideas of individuals or groups engaged in or operating under forms of collective behaviour and/or social control" (Alsayyad 2004, p.8). The research on urban informality largely focuses on developing an understanding about the functions and structure of informal groups/enterprises. However, some studies examine the nature and characteristics of informalities. Alsayyad (2004), for example, suggests that urban informality can be theorised as a marginal activity that is: (i) a temporary manifestation occurring as a transient feature within an organisation; or, (ii) closely connected to the formal structure and is an essential and permanent component or way of life. Thus the research focus is more about understanding the meanings of informalities, and how these meanings can create paradoxical situations (Meyerson 1991).

Studies on 'economic informality' focus particularly on illegal economic activity (Parry et el. 2007). These types of illegal activities take place 'below the radar' of government and can take many forms including the activities of unregistered small firms, street labour or large registered firms employing workers without written contracts (Oviedo, Thomas, and Karakurum-Özdemir 2009). Economic informality research has focused on: (i) identifying and measuring informal economic activities; (ii) the impact of the informal sector on an industry and nation e.g. labour market, unemployment, productivity, GDP etc; and, (iii) strategies for managing or controlling informal sectors e.g. regulation, legislation etc (Oviedo, Thomas, and Karakurum-Özdemir 2009; Parry et el. 2007). Here the focus is more on causal impacts of informality on economic outcomes and the effectiveness of regulation to deal with informality. It is important to be precise as to what kind of economic informality is studied (e.g. unregistered firms, unprotected workers, or the self-employed) so that appropriate approaches can be devised to study the problem (see Lewis and Hosein 2006; Wells 2001, 2007).

The conceptualisation of 'organisational informality' is largely underpinned by a sociological perspective. Morand (1995) notes that the term is "often used as conventional descriptors of social behaviour and social situations in organisation... [and] researchers generally have avoided rigorous attempts at construct definition and validation" (p. 833). He describes the terms 'informal' and 'informality' as referring "to social situations or gatherings that are generally characterized by behavioural spontaneity, casualness, and interpersonal familiarity". The distinction between informal and formal aspects of organisations translates into the interpretation of artefacts such as dress codes, jokes, behaviour in meetings etc. However, Morand's (1995) articulation of informality relates to interactional behaviours between actors in social construction and production; and the subsequent categorising of organisations (e.g. organic, inorganic, bureaucratic etc.) and their traits (e.g. innovative, agile etc).

Gajendran, T (2011) 'Investigating informality in construction: philosophy, paradigm and practice', Australasian Journal of Construction Economics and Building, 11 (2) 84-98 
More recently, organisational research has been active in highlighting the affects of new modes of communication, expanding divisions of labour, and increasing shifts towards nonhierarchical and self-coordinated organisations. These trends are together creating transient organisational boundaries and complex organisational set-ups. Informality in these newly devised contexts is viewed as a positive contributor to creativity and innovation. It plays a crucial role in developing links and trust among business partners operating in turbulent and uncertain business environments. Informalities can operate as flexible control mechanisms and fast solutions, in cases where formal mechanisms are impossible to manage or enforce. In contrast, informality in these contexts can also be seen as a threat to accountability and protocol, and even social justice (e.g. aiding discrimination). For example, Misztal (2000) suggests that the creation of the Asian economic crisis could be attributed to the failure of 'informal connections' reflected in practices of nepotism for instance, which led to a lack of accountability and transparency in organisations. Misztal (2000) subsequently argues that informality is best understood when explicitly compared with formality and suggests that maintaining a delicate balance between formality and informality is critical for order and control in new modes of organisations. This reinforces the interactional nature of informality as proposed by Morand (1995).

In construction projects, complexity, chaos and paradox, at least in part, can be attributed to the changing nature of organisations and the increasing emergence of informality as part of these contexts. The loosely coupled nature of construction project organisations (Dubois and Gadde, 2002) is conducive to a range of informalities in the practices and processes of construction. Chan and Raisanen (2009) suggest that any of the informality issues examined within a construction organisation are related to its practices, structures/systems, or social groupings (e.g. networks/clans of actors) in the context of a phenomenon (e.g. knowledge generation, safety management, competitiveness, learning process etc).

Informality issues can be related to interpersonal relations, informal leadership, behavioural control and informal communication (Hodgetts \& Hegar 2008). Activities associated with interpersonal relationships could include informal advice, trust, or communication. Informal leadership is associated with the development of power within non-formal structures: this may best be described as gate keeping or perimeter guarding. Behavioural control is a form of manipulation of members of an informal group using a variety of control strategies including establishing in-groups, coercion or persuasion.

\section{Taxonomies of Informality Research in Construction}

In this paper, it is argued that informality research can be conceptualised through four aspects, and that these aspects influence the design of the research approach/methodological paradigms, and vice versa. In addition, the role of the researcher is also noted, acknowledging the influence the researcher has on the execution of the study. The conceptual framework (see Figure 1), along with the interconnected methodological framework (see Figure 2) is described below, together with the role of the researcher. Subsequently, the frameworks are used to review how existing studies of informality are approached and framed. This will assist in identifying research approaches in studying construction informality and possible, more appropriate alternatives.

\section{Conceptual Underpinnings}

This conceptualisation is intended to serve as a guide in the selection of research strategies for informality studies. It identifies four related aspects that underpin taxonomies of informality research: the informality domain, research issue, legality/ethics of the issue, and informality visibility (Figure 1). 
Informality in the context of Construction

\begin{tabular}{|c|c|c|c|c|c|}
\hline \multicolumn{2}{|c|}{$\begin{array}{l}\text { Domain, Assumption and Issues influence (are } \\
\text { influenced by) a researcher's philosophical positions on } \\
\text { problem conceptualization \& methodology (Fig. 2) }\end{array}$} & \multicolumn{4}{|c|}{$\begin{array}{l}\text { Visibility and Legality influence the choice of research } \\
\text { methods and operations }\end{array}$} \\
\hline $\boldsymbol{4}$ & $\boldsymbol{4}$ & & $\boldsymbol{4}$ & & 4 \\
\hline $\begin{array}{l}\text { Informality } \\
\text { Domain }\end{array}$ & Research Issues & & Legality/ Ethicality & & $\begin{array}{l}\text { Visibility of } \\
\text { Informality }\end{array}$ \\
\hline $\begin{array}{l}\text { 1. Economic } \\
\text { View }\end{array}$ & $\begin{array}{l}\text { 3. Studies on the impact of } \\
\text { informalities on organizational } \\
\text { effectiveness }\end{array}$ & 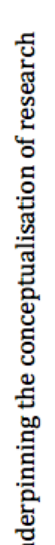 & $\begin{array}{l}\text { 1. Informality is } \\
\text { Illegal: Challenging } \\
\text { to deal with } \\
\text { research ethics } \\
\text { codes }\end{array}$ & 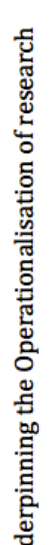 & $\begin{array}{l}\text { 1. Informality is } \\
\text { (partially) visible } \\
\text { via artifacts and } \\
\text { practices therefore } \\
\text { assessable }\end{array}$ \\
\hline $\begin{array}{l}\text { 2. Sociological } \\
\text { View }\end{array}$ & $\begin{array}{l}\text { 4. Understand informalities to } \\
\text { facilitates enhanced } \\
\text { organizational life }\end{array}$ & 跑 & $\begin{array}{l}\text { 2. Informality is } \\
\text { legal (but could be } \\
\text { immoral), thus less } \\
\text { challenging to deal } \\
\text { with ethics codes }\end{array}$ & 氖 & $\begin{array}{l}\text { 2. Informality is } \\
\text { not overtly visible } \\
\text { or concealed, thus } \\
\text { difficult to assess }\end{array}$ \\
\hline
\end{tabular}

Figure $1 \mathrm{~A}$ framework for conceptualising informality in construction

Informality domain refers to the discipline-based attributes influencing the core conceptualisation of informality research, which are broadly divided into economic and sociological domains. As the areas of research in construction management are diverse, different discipline-based assumptions and training can influence the treatment and approach of studies and assessments (Rooke \& Kagioglou 2007; Runeson and Skitmore 2008). For example, an economic view of informality is often focused on identifying and quantifying illegal economic activities and devising regulations and strategies to manage them. The sociological view is focused on 'structural and interactional' issues of socially constructed realities. Across both approaches, ethical and moral aspects are central to the conceptualisation and operationalisation of informalities research (Denzion and Lincoln 2005).

The research issues are influenced by the attributes of the 'informality domain' (as identified in Figure 2). In the context of this paper, four general research issues are identified: (i) assessing actors' interpretations of informal interactional orders; (ii) developing meanings of informality issues and their associated characteristics via observed behaviours (e.g. bodily postures, conversational interruptions, phonological slurring, etc), or deciphering unobservable deep beliefs (values, assumptions etc); (iii) assessing the impact of informality on organisational effectiveness; and, (iv) understanding informality in terms of enhancing organisational life (not directly associated with improvements in organisational effectiveness). Each of the issues can be used to frame research into informality aspects e.g. interpersonal relations, informal leadership, behavioural control and informal communication etc, could be researched via one or mix of the four-research issue.

The level of visibility of an informality issue is dependent on how it is conceptualised. For example, interpersonal relations in an organisation can be studied via more visible rituals 
depicted by artifacts (e.g. jokes, form of language), or via less visible trust and advice networks. The visibility of the issues has a significant influence on the methodological approach.

Legality/illegality of the aspect under study has a significant influence on the operational design and choice of research method. Almost all universities are bound by research ethics protocols that aim to minimise the risks associated with research design and maximise the welfare of the participants (see Australian Government 2007). Research projects studying illegal issues (even in the likelihood of inadvertent identification) are imposed with additional statutory obligations. The minimal obligations attached to anonymous illegal studies could attract researchers to engage with methods that offer anonymity. Research projects studying unethical and immoral informal activities (i.e. not explicitly illegal) are not subjected to these additional statutory obligations. However, it can be argued that these studies should nevertheless be treated with sensitivity, and the findings should not be exploited. Ethics is not solely about 'procedural ethics' that seeks compliance with established protocols (see Guillemin and Gillam, 2004; Brydon_Miller 2008; O'Leary 2004). All research is value-ridden (as opposed to value-free), which makes it is essential that researchers understand the value system and its impact on their own research position and approach (Corbin and Struss 2008; Christians 2005).

It is important to note that the interactions between these five aspects are not linear. Conceptualising informality as a research problem is a highly complex process involving numerous aspects under consideration simultaneously (e.g. disciplines, assumptions, research issues). Moreover, this process is closely connected with methodological approaches to studying informality, as revealed in the following and interrelated methodological framework.

\section{Research Approaches and Processes}

Figure 2 identifies four processes in the methodological design of research: 1- Selecting a methodology: paradigms/ worldviews, 2- Selecting a methodology: research strategy, 3Selecting a research method: data collection process and 4- Selecting a research method: techniques

Two key terminologies - methodology and method - are used in Figure 2 to describe the methodological practices in informality research. Strauss and Corbin (1998) describe methodology is "[a] way of thinking about and studying social reality" and method as "[a] set of procedures and techniques for gathering and analysing data" (p3). Morse and Richards (2002) use the term 'research strategy' in lieu of methodology and describe research strategy as "a way of approaching data with a combination of techniques that are ideally consistent with the method the researcher has chosen to use. ... [T] refers to a more or less consistent and coherent way of thinking about and making [collecting] data, way of interpreting and analysing data, and way of judging the resulting theoretical outcome" ( $p$ 10). The term 'technique' to refers to a way of attempting or completing research tasks (e.g. data coding). Although techniques themselves do not indicate which method is employed in the research, the ways in which the techniques are applied could indicate likely research methods to be used.

The first two processes are related to the choice of a methodology, worldview(s), and research strategy(ies) that accommodates that worldview. The last two processes are related to the choice of methods that focus on data collection and analysis techniques. Despite the numerous combinations of possible research practices for informality research, some combinations may not be philosophically aligned. In this paper, the aim is to provide a framework for research that would encourage alignment between worldview and methods.

Gajendran, T (2011) 'Investigating informality in construction: philosophy, paradigm and practice', Australasian Journal of Construction Economics and Building, 11 (2) 84-98 


\begin{tabular}{|c|c|c|c|}
\hline $\begin{array}{l}\text { Process 1: Selecting a } \\
\text { Methodology: } \\
\text { Paradigms/ worldviews }\end{array}$ & $\begin{array}{l}\text { Process 2: S } \\
\text { a Methodolo } \\
\text { Research Str }\end{array}$ & $\begin{array}{l}\text { Process 3: Selecting } \\
\text { a Research Method- } \\
\text { Data collection }\end{array}$ & $\begin{array}{l}\text { ss 4: Selecting } \\
\text { earch Method- } \\
\text { liques/analysis }\end{array}$ \\
\hline $\begin{array}{l}\text { Post-positivism } \\
\text { Constructivism } \\
\text { Interpretivism } \\
\text { Critical Theory } \\
\text { Hermeneutics- } \\
\text { Emancipation } \\
\text { Critical Realism } \\
\text { Pragmatism (as proposed } \\
\text { by Creswell and Clerk } \\
\text { 2007) }\end{array}$ & $\begin{array}{l}\text { Case study } \\
\text { Ethnography } \\
\text { Action research } \\
\text { Grounded Theory } \\
\text { Phenomenology } \\
\text { Ethnomethodology } \\
\text { Discourse analysis } \\
\text { Semiotics }\end{array}$ & $\begin{array}{l}\text { Surveys (open ended- } \\
\text { close ended; postal- } \\
\text { email-online etc) } \\
\text { Observation } \\
\text { Interviews (face to } \\
\text { face-telephone etc) } \\
\text { Focus groups } \\
\text { Diaries } \\
\text { Artefacts, documents, } \\
\text { and records } \\
\text { Visual (video) methods }\end{array}$ & $\begin{array}{l}\text { Descriptive statistics } \\
\text { Inferential statistics: } \\
\text { Paramedic and Non- } \\
\text { Parametric statistical } \\
\text { techniques } \\
\text { Coding: (Open codes, } \\
\text { Axial Codes, Selective } \\
\text { codes, Memos, } \\
\text { diagrams etc) }\end{array}$ \\
\hline
\end{tabular}

Figure 2 A framework of possible research methodologies for informality research

Synthesis based on Strauss and Corbin (1998); Scale (1999); Denzin \& Linclon (2005); Guba and Lincoln (2005), Clerk and Creswell (2007); Corbin and Strauss (2008); Bernard and Ryan (2010)

Selecting a methodology which aligns with the paradigm (Process 1) and strateg(ies) (Process 2) interacts with the conceptualisation of informality issues (i.e. the domain and issues). The worldview or paradigm affiliation (Process 1) of a researcher is intrinsic to the way a research issue is conceptualised (Morgan and Smircich 1980). As indicated earlier, this means conceptualisation of research issues occurs in multiple and interactive layers. Varieties of post-positivist or constructivist philosophies "enable researchers to deal with complex layered and often unobservable strata of reality that impact upon our action and thinking" (Joseph and Roberts 2004, p1). One of the eight worldviews proposed in the Process 1 in Figure 1 could conceptually underpin informality research. The subtlety of the paradigm variations demand deep engagement with the literature to perceive the differences. Moreover, it is instructive to map the development of philosophical alternatives beyond the dominance of social constructivism and interpretivism. The tensions between emerging constructivist/interpretivist/critical theorist philosophies is evident in literature (Joseph and Roberts, 2004). In essence, during Process 2, researchers conceptualise their research issues with a worldview they uphold (if they are fundamentalists) or the worldview they want to adopt (if they are pragmatists). Researchers need to carefully evaluate and respond to critiques of the chosen worldview and why it will deliver meaningful outcomes.

As an example researchers' deep assumption about the nature of informality, whether it is a temporary or permanent phenomena, could influence research conceptualisation and paradigm position. Researchers, assuming informality as a permanent aspect, may not seek to identify strategies to eradicate informality. They rather conceptualise their research with an interpretative, hermeneutic-emancipatory tradition that enables them to understand the meaning and/or transform the socially constructed realities by liberating the members from 
their traditionally held beliefs (Alvesson and Willmott 1992; Alvesson 2002). Assumptions of the temporary nature of informality could lead to a technical and rational approach to eradicate informality underpinned by post-positivist tradition [Refer Figure 2].

However, keeping pace with the rapidly emerging paradigm variations in the qualitative methodologies (the 'isms' revolution) is challenging (Denizen and Lincoln 2005). Most evolving paradigms are arguably variations to existing post-positivist paradigms, accommodating deviations in ideology or research process (Joesph, and Roberts 2004). The evolution of alternative paradigms can be observed as staying true to the cause of the fundamentals of post-positivism: that is to acknowledging multiple worldviews (Denizin and Lincoln 2005). The evolution of paradigms constantly challenges the prevailing worldviews (constructed by the ontological and epistemological positions) that may stand in the way of developing a clear understanding of a problem (O'Leary 2004; Bryman 2008).

Process 2 is about identifying a research strategy that complements the choice of worldview(s). A research project designed to study informality could combine multiple strategies. As an example, 'ethnography' is complementary to 'case studies' and 'grounded theory' (see Barrett and Sutrisna 2009). In the case of a construction project, the nature of the project and identification of the boundaries (defining the social units of which it is comprised) are best investigated using case studies. The case study is an overarching research strategy rather than simply a data collection method or a research design concept (Yin 1994). As Stake (1995, p. 2) states: "the case study methodology/strategy allows any selected method to "study a case analytically or holistically, entirely by repeated measure [positivist] or hermeneutically, organically or culturally and by mixed methods..." (Stake 2005, p. 443). Therefore, the case study could be designed in combination with phenomenology, ethnomethodology, discourse analysis and semiotics.

The methodological position will influence the selection of the appropriate methods for data collection (Process 3) (and vice versa). In theory, the choice of a data collection method should be predominantly underpinned by the methodology. However, in practice, numerous other considerations, such as ethical protocols or the cooperation of participants tend to act as constraints on the choice of data collection methods. Although methods supporting a positivist paradigm are reduced to surveys and published numerical data, a trend has developed for the use of quantitative methods to analyse the results arising from nonpositivist methods such as 'key word searches' as part of context analysis (Bernard and Ryan 2010). Almost all non-positivist methodologies could use interviews and focus groups as data collection methods. In addition, ethnographic studies could use observations and any relevant artefacts/documents as data. Patterns of informal behaviour can also be studied with visual (video) methods and use of diaries.

The selection of research analysis? techniques (Process 4) is also related to the selection of methods and methodology. Analysis techniques range from quantitative (e.g. inferential and descriptive statistics) to qualitative techniques (e.g. coding and thematic analysis). Although coding techniques are used in quantitative analysis they are also commonly understood as a key part of a qualitative approach. Strauss and Corbin (1998) have provided an extensive discussion on coding process (e.g. open codes, axial codes, selective codes, memos, diagrams etc. Conversion analysis technique is central to discourse analysis. Thematic analysis identifies themes emerging from data and is a technique that could be applicable to most qualitative approaches (See Bernard and Ryan (2010) for guiding the operationalisation of these methods).

\section{The Researcher being the 'Research Instrument'}

Designing an appropriate research approach is only part of good and meaningful research. This establishes the ideology underpinning the research and the processes that are followed in the design and execution of the research. However, the fundamental concern is - how the 
researcher will execute the methodology? who is the instrument, in arriving at a meaningful outcome? In contrast to quantitative research, where researchers rely upon validated statistical instruments, qualitative research assumes that researchers themselves are the instruments. Corbin and Strauss (2008) argue that good qualitative research emanates form the researchers who share the characteristics of having a humanistic bent, curiosity, creativity and imagination. However, the key characteristic that distinguishes good qualitative researchers is the ability of the researchers to deal with risk and to manage ambiguity. Moreover, researchers who develop trust and confidence in the self as the research instrument (as opposed to established tools and techniques) generally maintain high-quality and ethical research practices. Designing quality research then, involves the selection of appropriate research practices that maintain the adequacy of the project and that deliver meaningful outcomes, as purposively directed by the researcher (see Dainty, 2008 on the principles of methodological plurality).

\section{A Selected Review of Informality Research}

This section reviews methodologies used in studying informalities in construction, based on selected published work in the area. This review includes papers in which informality is dealt with implicitly and/or explicitly, and is divided between those papers that take an economic perspective on informality and those that assume a sociological approach in examining informality. It should be noted that the selected studies are not a complete representation of informality studies in construction. However, this review can inform a range of research approaches that can be discussed in the context of Figures $1 \& 2$. This can assist in developing an understanding of the taxonomies of methodological approach that can be used for studying different informality issues.

\section{Review of Informality Studies from the Economic Perspective}

A study by Lewis and Hosein (2006) focused on estimating the size of the informal (hidden) construction labour force in Trinidad and Tobago (T\&T). That is, identifying the nature of illegal labour and quantifying the extent of informal (illegal) labour employed in construction projects/sectors in a particular region. Lewis and Hosein (2006) rationalised the methodological approach using anecdotal evidence and citing the difficulty in obtaining reliable statistical data on illegal sectors or activities within the construction industry. As a result, the study used published statistics from a number of sources to then estimate the extent of informal construction labour in T\&T. The research thus drew on publicly available and published documents and identified some of the ethical challenges in collecting primary data to identify and quantify the hidden sector.

The paper by Wells (2001) focused on revealing the informal sector in the context of capital formation in less developed economies. In this paper, the illegality of the informal sector is not overtly discussed. Like the previous study, the paper is based on observations and/or discussions with participants and published data. It is difficult to gauge the assumptions about the temporary/permanent nature of the informality in this type of study. The author explicitly mentioning not to interpret the findings of the study along the racial context, highlights the ethical issues confronting the researchers beyond reporting on their study.

Oviedo, Thomas, and Karakurum-Özdemir (2009) identify a number of other methods that could be used to study economic informality. The approaches are classified as direct (micro) methods and indirect methods (macro) methods. The micro methods could employ voluntary surveys (Nugent, and Sukiasyan 2009.), interviews and tax audits (Oviedo, Thomas, and Karakurum-Ozdemir 2009). Use of the survey method, specifically anonymous surveys, to collect primary data is relatively less challenging to gaining ethical approval than some comparable methods. The anonymity of personnel associated with any illegal activities minimises the risk to, and responsibilities of, the researchers and institutions conducting the study. The interview method could pose challenges if actors involved in the illegal informal

Gajendran, T (2011) 'Investigating informality in construction: philosophy, paradigm and practice', Australasian Journal of Construction Economics and Building, 11 (2) 84-98 
sector are identified, as ethical protocols would require that all illegal activity is reported to the relevant authorities. With tax audits, the collection of private and identifiable data could also prove ethically challenging. Moreover, any identification of informality associated with tax evasion could be treated as a criminal activity-again, researchers are required to notify such activity to appropriate authorities. However, tax-based analysis can be conducted using secondary published data, if available. These methods include studying the discrepancy between aggregate and income expenditure, or the discrepancy between total labour force and formal employment and physical input of resources (e.g. use of electricity or water consumption).

In essence, economic informality studies are dominated by positivist methods, although there is room for the use of post-positivist methods.

\section{Review of Informality Studies from the Sociological Perspective}

Ethnography is a common approach to exploring informality from a sociological perspective. This approach is used as a means for exploring cultural aspects of human organisation (Geertz 1975; Morse \& Richards 2002; Schein 2004), and can be adopted to make sense of partly visible emergent informalities. For example, Baarts (2009) used ethnography to study collective individualism as an informal emergent social process relating to construction site safety practices (i.e. Research Issue 2, Figure 1). Ethnography can unearth hidden informal practices as part of the culture of an organisation. In this study, the researcher become part of the cultural group, conducting observations during the normal course of work. The researcher questioned and evaluated the ethical concerns and personal prejudices in an explicit manner in the conceptualisation and operationalisation of the research study. The descriptions made during the site observations and data from semi-structured interviews were used to create meaning and develop an understanding of the informal social process.

Pink et al. (2010) discuss the opportunities offered by ethnographic approaches in developing better understandings of social phenomena. This study, through the ethnographic process, developed an understanding of invisible routes of communication in construction sites employing migrant workers (e.g. Research Issue 4, Figure 1). The use of photographic and video-based data in addition to conventional ethnographic data is also adopted. Pink et al. (2010 p. 649) indicate the "essential criteria [of their study] is that the researcher retains the reflexive awareness of how her or his work is informed by theory and a self-consciously considers how theory and practice remain in dialogue though the ethnographic process". The focus on developing meaning from social practices to understand organisational life fits with the hermeneutic-emancipatory paradigm. The above two studies analysed both visible (using observations) and hidden aspects (using in-depth discussions) of informalities. However, they did not report any ethical challenges in executing the research design.

Gores and Emmitt $(2007,2009)$ examined the informal aspects of the communication process during construction progress meetings (e.g. Research Issue 1, Figure 1). The study involved the analysis of observable/visible physical behaviours and linguistic interactions during site meetings across 10 projects. This approach was used to unearth the 'not so' visible socio-emotional interactions influencing informal relationships among the team members. They used observation methods and 'interaction analysis process' approach (a qualitative approach to generate quantitative data) to analyse the communication process. The difficulties faced with executing the conceptual research design in practice are highlighted.

A study by Styhre, Josephson and Knauseder (2004) implicitly deals with informalities associated with the learning capabilities of organisation networks (e.g. Research Issue 2, Figure 1). They employed case study and action research strategies using individual interviews, group interviews and published documents as data to identify informal networks.

Gajendran, T (2011) 'Investigating informality in construction: philosophy, paradigm and practice', Australasian Journal of Construction Economics and Building, 11 (2) 84-98 
Bresnen (2009) employed an inductive approach to study emergent practices of partnering through a practice-based approach. The study used interviews, documents and observations to grasp the emergent nature of partnering practice (e.g. Research Issue 2, Figure 1). Furthermore, the paper discusses alternative methodologies and methods for generating knowledge, reinforcing the need for multiple lenses to study informalities.

Barrett and Sutrisna (2009) have advocated the use multiple approaches within the context of a case study strategy for generating meaning from social phenomena (e.g. Research Issue 3, Figure 1). However, caution in the abstraction process is urged to maintain the relevant meanings of events, and to not confuse the meanings by removing the context. Their study on understanding process in construction projects was conceived within the critical realism paradigm, using case study and grounded theory strategies. The critical realism paradigm enables them to assume both objective and subjective realities of constructs associated with their study. They used condition consequence matrices and cognitive maps to show relationships between concepts and to identify some causal relationships.

\section{Discussion}

The above review highlights the diverse, but effective methodologies and methods employed in studying informality and emergence in construction. The studies on economic informalities, due to difficulties in gathering reliable primary data, have largely used anecdotal evidence and existing published data in identifying and quantifying informalities. Studies from a sociological perspective employ multiple strategies including case study, ethnography, action research, and grounded theory, using different types of data gathering techniques, including observations, interviews, published documents etc. It can be inferred that all the above studies, except Gorse and Emmitt (2007, 2009), used qualitative methodology as part of a non-positivist tradition. Although not explicitly stated, all of the sociological studies fall into constructivism, interpretativism, and hermeneutic-emancipation paradigms, except Barrett and Sutrisna (2009) who assumed a critical realism framework.

From the literature, there clearly remains limited use of discourse analysis (Kao, Green, and Larsen 2009) and ethnomethodology strategies (Hugill 2001, c.f. Gorse and Emmitt 2009; Rooke, Koskela, and Kagioglou, 2009) to study informality. Discourse analysis, phenomenology and ethnomethodology are focused on understanding realities based on the use of language in written or oral form. These strategies are closely aligned to the interpretativist paradigm. Discourse analysis can help to reveal the types of informal structures of the language used by different project team members (e.g. architect, contractor, engineer). Phenomenology and ethnomethodology are focused on "micro-social interactions- that is interaction on a small scale, between individuals or within small groups" (Seale, 1999 p. 30) can also provide different lenses to study informality as a social construct.

The discourse analysis, phenomenology and ethnomethodology in the context of constructivism, interpretativism and hermeneutic emancipation paradigms can provide a sound base to develop an in-depth understanding of informalities through the use of language. This enables transformation of, or liberation from, the traditionally held beliefs and practices underpinning informality in construction (Alvesson and Willmott 1992).

The use of semiotics could deal with analysis of structures, generative mechanisms and practices beyond language. This can provide an alternative to critical theorists who reject the use of discourse strategies to explain causality, keeping in line with the hermeneutic emancipation tradition. Therefore, semiotic strategies, conceived within the critical realism paradigm could offer a better research approach to study informality enabling causal analysis while maintaining some the rich attributes of non-positivist paradigms (Fairclough, Jessop and Sayer, 2004). 


\section{Conclusions}

Informality is a significant part of the practices and processes of construction project organisations. Accordingly, informality needs to form part of research conducted on the construction sector. However, informality can be a difficult subject to research due to its often intangible and invisible nature. In this paper, a number of approaches, methodologies and methods are put forward as part of a guiding framework for research in this area. It is argued that a carefully developed research project can aid in understanding and uncovering informality in construction projects and, in turn, can help identify potentially problematic paradoxes that often emerge from these informalities. To this end, the paper proposes interrelated conceptual and methodological frameworks for research on informality. Indeed, it is proposed that the methodological process involves identifying paradigm(s) within which the research is conceptualised, which then influences the strategies and research methods adopted for collecting and analysing data-and vice versa. First, four key dimensions were identified as vital when conceptualising 'informality' research: the discipline context (economics or sociology), nature of the research issues, ethical/legal dimensions and visibility of the informality, with the significant connections between the conceptual and operational aspects of the research acknowledged. Second, the methodological framework presents four processes associated to research design: 1- Selecting a methodology: paradigms/ worldviews, 2- Selecting a methodology: research strategy, 3- Selecting a research method: data collection process and 4- Selecting a research method: techniques.

It is argued that both frameworks are equally important and iterative in nature. Practical (ethical and operational) considerations of conceptual research design are paramount for developing meaningful outcomes. Finally, these frameworks were used to investigate existing literature on this subject, as a way of identifying advantages, disadvantages and gaps in the research. It is evident (within the limitations of this brief review) that the case study strategy, ethnography and action research, are commonly and effectively used to study informality from a sociological perspective. It is proposed that critical realism could prove to be a worthwhile paradigm for studying informality in construction, because of its ability to connect. Furthermore, it is argued that alternative methodological approaches, such as ethno-methodology, phenomenology and semiotics could add richness to informality studies.

This paper deliberately avoids prescribing the 'best' approach to studying informality issues. From the frameworks developed and the review of existing literature, it is argued that a prescriptive approach in studies of informality would be ineffective in coping with the complex social phenomenon of informality. Instead, a flexible and guiding framework is proposed to help researchers develop appropriate and well-considered frameworks that produce meaningful outcomes for understanding and identifying informality in the construction sector.

\section{References}

Alderman, N. and Ivory, C. (2007) 'Partnering in major contracts: Paradox and metaphor', International Journal of Project Management, 25 (4), 386-393

Alsayyad, N. (2004) Urban Informality: Transnational Perspectives from the Middle East, Latin America, and South Asia, Lexington Books, Lanham

Alvesson, M. (2002) Understanding Organisational Culture, SAGE Publications, London

Alvesson, M. and Willmott, H. (1992) 'On the idea of emancipation in management and organizational studies', The Academy of Management Review, 17 (3), 432-464

Australian Government (2007) National Statement on Ethical Conduct in Human Research, Australian Government, ACT 
Baarts, C. (2009) 'Collective individualism: the informal and emergent dynamics of practicing safety in a high-risk work environment', Construction Management and Economics, 27 (10), 947-957

Baccarini, D. (1996) 'The concept of project complexity- A Review', International Journal of Project Management, 14 (4), 201-204

Barrett, P. and Sutrisna, M. (2009) 'Methodological strategies to gain insights into informality and emergence in construction project case studies', Construction Management and Economics, 27, 935-948

Berggren, C., Soderlund,J. and Anderson, C. (2001) 'Clients, Contractors, and Consultants: The consequences of Organizational Fragmentation in Contemporary Project Environments', Project Management Journal, 32 (3), 39-48

Bernard, H. R. and Ryan, G. W. (2010) Analysing Qualitative Data, SAGE, Thousand Oaks

Bourne, L. and Walker, D. H. T. (2005) 'The Paradox of Project Control', Team Performance Management, 11 (5/6), 649-660

Bresnen, M. (2009) Living the dream? Understanding partnering as emergent practice. Construction Management and Economics, 27 (10), 923-933

Bresnen, M. Edelman, L. Newell, S. Scarbrough, H. and Swan, J. (2003) 'Social practices and the management of knowledge in project environments', International Journal of Project Management, 21 (3), 157-166

Bresnen, M. Goussevskaia, A. and Swan, J. (2005) 'Editorial: Managing projects as complex social settings', Building Research \& Information, 33 (6), 487-493

Bresnen, M. J. Ford, J. R. Bryman, A. E. Keil, E. T. Beardsworth, A. D. and Wray, K. (1986) 'Labour recruitment strategies and selection practices on construction sites', Construction Management and Economics, 4 (1) 37-55

Brydon-Miller, M. (2008) Ethics and Action Research: Deepening our commitment to principles of social justice and redefining systems of democratic practice, Reason, P. and Bradbury, H. (eds.), Action Research: Participative inquiry and practice, 199-210

Bryman, A. (2008) Social Research Methods, Oxford University Press, Oxford

Byrne, J. Clarke, L. and Meer, M. V. D. (2005) 'Gender and ethnic minority exclusion from skilled occupations in construction: a Western European comparison', Construction Management and Economics, 23 (10), 1025-1034

Chan, P. W. and Raisanen, C. (2009) 'Editorial: informality and emergence in construction', Construction Management and Economics, 27 (10), 907-912

Christians, C. G. (2005) Ethics and Politics in Qualitative Research, Denzin, N. K. and Lincoln, Y. S. (eds.), The Sage handbook of qualitative research, SAGE. Thousand Oaks

Cookep-Davies, T. J. Cicmil, S. Crawford, S. and Richardson, K. (2007) 'We are not in Kansas anymore, Toto: mapping the strange landscape of complexity theory and its relationship to project management', Project Management Journal, 38 (2), 50-51

Corbin, J. and Struss, A. (2008) Basics of Qualitative Research, 3rd. End, SAGE, Thousand Oks.

Creswell, J. W. and Clark, V. L. P. (2007) Designing and conducting mixed method research, Sage, Thousand Oaks

Dainty, A. (2008) Methodological Pluralism in construction management research, Knight, A. and Ruddock, L. (eds.), Advanced methods in the built environment, Wiley-Blackwell, West Sussex, 1-13 
Denzin, N. K. and Lincoln, Y. S. (2005) Introduction: The discipline and practice of qualitative research, Denzin, N. K. and Lincoln, Y. S. (eds.), The Sage handbook of qualitative research, SAGE. Thousand Oaks.

Dubois, A. and Gadde, L.-E. (2002) 'The construction industry as a loosely coupled system: implications for productivity and innovation', Construction Management and Economics, 20

Fairclough, N. Jessop, B. and Sayer, A. (2004) Crtical realism and semiosis, Joesph, J. and Roberts, J. M. (eds.), Realism Discourse and Deconstruction, Routledge. London, 23-42

Geertz, C. (1975) The Interpretation of Cultures, London, Hutchinson

Geraldi, J. G. (2008) 'The balance between order and chaos in multi-project firms: A conceptual model', International Journal of Project Management, 26, 348-356

Gorse, C. A. and Emmitt, S. (2007) 'Communication behaviour during management and design team meetings: a comparison of group interaction' Construction Management and Economics, 25, 1195-1211

Gorse, C. A. and Emmitt, S. (2009) 'Informal interaction in construction progress meetings', Construction Management and Economics, 27 (10), 983-993

Guba, E. G. and Lincoln, Y. S. (2005) Paradigmatic controversies, contradictions and emerging confluences, Denzin, N. K. and Lincoln, Y. S. (eds.), The Sage handbook of qualitative research, SAGE. Thousand Oaks, 191-216

Guillemin, M. and Gillam, L. (2004) 'Ethics, Reflexivity, and "Ethically Important Moments" in Research', Qualitative Inquiry, 10 (2), 261-280

Hodgetts, R. M. and Hegar, K. W. (2008) Modern Human Relations at work, 3rd. End. Thomson, Australia

Joesph, J. and Roberts, J. M., Eds. (2004) Realism Discourse and Deconstruction, Routledge, London

Jones, M. (2004) Critical realism, critical discourse analysis and concrete research, Joesph, J. and Roberts, J. M. (eds.), Realism Discourse and Deconstruction, Routledge, London, 4367

Kao, C.-C. Green, S. D. and Larsen, G. D. (2009) 'Emergent discourses of construction competitiveness: localized learning and embeddedness', Construction Management and Economics, 27 (10), 1005-1017

Lewis, T. M. and Hosein, R. (2006) 'An estimation of the size of the hidden labour force in construction in Trinidad and Tobago', Construction Management and Economics, 24 (8), 805-815

Lingard, H. and Rowlinson, S. (2005) Occupational health and safety in construction project management. Spon Press, Oxon

Marrewijk, A. v. Clegg, S. R. Pitsis, T. S. and Veenswijk, M. (2008) 'Managing public-private megaprojects: Paradoxes, complexity, and project design', International Journal of Project Management, 26 (5), 591-600

Meyerson, D. E. (1991) Acknowledging and uncovering ambiguities in cultures, Frost, P. J. More, L. F. Louis, M. R. Lundberg, C. C. and Martin, J. (eds.), Reframing Organisational Culture, Sage. California, 254-270

Misztal, B. A. (2000) Informality: social theory and contemporary practice, Routledge New York

Moldoveanu, M. (2004) An intersubjective measure of organizational complexity: A new approach to the study of complexity in organizations. E:CO, 6 (3), 9-26 
Morand, D. A. (1995) 'The role of behavioral formality and informality in the enactment of bureaucratic versus organic organisations', Academy of Management Review, 20 (4), 831872

Morgan, G. and Smircich, L. (1980) 'The case for qualitative research', Academy of Management Review, 5, 471-500

Morse, J. M. and L. Richards (2002) Readme First for a User's guide to Qualitative Methods, California, Sage Publications

Nugent, J. B. and G. Sukiassyan (2009) 'Alternative strategies for firms in oppressive and corrupt states: Informality or formality via business associations?', Contemporary Economic Policy, 27 (4), 423-439

O'Leary, Z. (2004) The essential guide to doing research, SAGE, London

Oviedo, A. M. Thomas, M. R. and Karakurum-Özdemir, K. (2009) Economic Informality: Causes, Costs, and Policies - A Literature Survey, Washington

Perry, G. E. Maloney, W. F. Arias, O. S. Fajnzlber, P. Mason, A. D. and Saavedra-Chanduvi, J. (2007) Informality: Exit and Exclusion. The World Bank, Washington, D. C.

Pinka, S. DylanTutt Andrew Dainty and Alistair Gibb (2010) Ethnographic methodologies for construction research: knowing, practice and interventions. Building Research and Information, 38 (6), 647-659

Remington, Kaye, Zolin, Roxanne, and Turner, Rodney (2009) 'A model of project complexity: distinguishing dimensions of complexity from severity', In Proceedings of the 9th International Research Network of Project Management Conference, IRNOP

Rooke, J. A. and Kagioglou, M. (2007) 'Criteria for evaluating research: the unique adequacy requirement of methods', Construction Management and Economics, 25 (9), 979-987

Rooke, J. A. Koskela, K. and Kagioglou, M. (2009) 'Informality in organization and research: a review and a proposal', Construction Management and Economics, 27 (10), 913-922

Runeson, G. and M. Skitmore (2008) 'Scientific Theories', In Advanced methods in the built environment, A. Knight and L. Ruddock, West Sussex, Wiley-Blackwell: 75-84

Schein, E. H. (2004) Organizational culture and leadership, San Francisco, Jossey-Bass

Seale, C., Ed. (1999) Researching Society and Culture, SAGE, Thousand Oks

Senaratne, S. and Sexton, M. (2008) 'Managing construction Project change: a knowledge management perceptive', Construction Management and Economics, 26 (12), 1303-1311

Small, J. and Walker, D. (2010) 'The emergent realties of project praxis in socially complex project environments', International Journal of Managing Projects in Business, 3 (1), 147-156

Stake, R. E. (2005) The Art of Case Study Research, The Sage handbook of qualitative research, M. K. Denzin and Y. S. Lincoln, Thousand Oakes California, SAGE Publications: 443-465

Strauss, A. and Corbin, J. (1998) Basics of Qualitative Research, 2. End. SAGE Publications, California

Styher, A. Josephson, P.-E. and Knauseder, I. (2004) Learning capabilities in organisational networks: case studies of six construction projects. Construction Management and Economics, 22 (9), 957-966

Wells, J. (2001) Construction and capital formation in less developed economies: unraveling the informal sector in an African city. Construction Management and Economics, 19 (3), 267274

Yin, R. K. (1994) Case study research: design and methods, Thousand Oaks, California, Sage 